\title{
Ivabradine in Chronic Heart Failure
}

\author{
Hadeer Eid Eliwa $^{* a}$, Ebtissam Darweesh ${ }^{\mathrm{a}}$, Nagwa Sabri ${ }^{\mathrm{b}}$, Naglaa Bazan \\ ${ }^{a}$ Clinical Pharmacy Department, Faculty of Pharmaceutical Sciences and Pharmaceutical Industries, Future \\ University in Egypt, Cairo, Egypt \\ ${ }^{\mathrm{b}}$ Clinical Pharmacy Department, Faculty of Pharmacy, Ain Shams University, Cairo 11566, Egypt \\ ${ }^{\mathrm{c}}$ Critical Care Medicine Department, Cairo University Hospitals, Cairo, Egypt
}

\begin{abstract}
Heart failure (HF) is an epidemic of cardiovascular disease resulting in impaired function and worsened quality of life (QOL) of HF patients. Increased heart rate correlates with poor outcomes in these patients; therefore, its reduction may be beneficial in reducing hospitalization for worsening HF. Guideline therapy recommendation for $\beta$-blocking agents is a standard cornerstone for the treatment of HF. Despite, the dose adjustment of $\beta$-blockers for patients who cannot withstand the target dose, desired goal heart rate reduction is unfortunately not always reached. Additionally, $\beta$-blockers are contraindicated for certain patients. Ivabradine decreases the heart rate through inhibiting the cardiac pacemaker current $\left(\mathrm{I}_{f}\right)$ without having any influence on the sympathetic nervous system. The drug has been approved by the United States Food and Drug Administration in 2015. In 2012, ivabradine use was included in the European Society of Cardiology (ESC) guidelines for the management of HF, to be used alongside $\beta$-blockers or as a safer substitute. This short review aimed to discuss the ivabradine use in both reduced and preserved ejection fraction HF patients. Ivabradine was found to be generally tolerable and safe. Efficacy for HF patients with systolic dysfunction has been confirmed, however, in HF patients with diastolic dysfunction, it is yet to be extensively evaluated. Moreover, the role of ivabradine in HF patients with Atrial Fibrillation (AF) is currently under investigation.
\end{abstract}

Keywords: Ivabradine; Heart Failure; Heart Rate; Quality of Lif.

*Correspondence | Hadeer E Eliwa; Clinical Pharmacy Department, Faculty of pharmaceutical sciences and pharmaceutical industries, Future University in Egypt, Cairo, Egypt. Email: hadeir.eid@fue.edu.eg

Citation | Eliwa HE, Darweesh E, Sabri N, Bazan N, 2020. Ivabradine in Chronic Heart Failure. Arch Pharm Sci ASU 4(1): $36-46$

DOI: 10.21608 /APS.2020.2001.1023

Print ISSN: 2356-8380. Online ISSN: 2356-8399.

Received 29 January 2020. Accepted 19 February 2020.

Copyright: ${ }^{\circ} 2020$ Eliwa et al. This is an open-access article licensed under a Creative Commons Attribution 4.0 International License (CC BY 4.0), which permits unrestricted use, distribution, and reproduction in any medium, provided the original author(s) and source are credited. Published by: Ain Shams University, Faculty of Pharmacy

\section{INTRODUCTION}

Despite the medical advances in therapeutic agents developed for controlling HF, it continues to be a global health burden. Its prevalence is about $1-2 \%$ of the adult population in developed countries. Recent reports report the expectation that prevalence may double in the future [1-4].
Age has a direct relationship with the occurrence of HF. The rate is $1-2 \%$ of the population with ages less than 55 and reaches $10 \%$ for those older than 75 years [5]. Half of the burden of $\mathrm{HF}$ is caused by heart failure with reduced ejection fraction (HFrEF) and the other half by heart failure with preserved ejection fraction HFpEF [6]. 
In Egypt, the first national large-scale prospective multi-center registry to study $\mathrm{HF}$ patients was published in 2015. Demographics of $2145 \mathrm{HF}$ patients were analyzed and compared to those from other countries in the (ESC-HF-LT) registry. Of the patients included in the registry, $68.8 \%$ of patients had Acute Heart Failure (AHF), while the rest had Chronic heart failure (CHF), and $67.9 \%$ of the total patients were males.

Medications used for the pharmacological management of HF include angiotensinconverting enzyme (ACE) inhibitors, angiotensin receptor blockers (ARBs), $\beta$-blockers, mineralocorticoid antagonists (MRAs), diuretics, hydralazine/ nitrates, and digoxin. Ivabradine was approved in 2015 to improve clinical outcomes in HF patients with persistent symptoms of HF, despite maximum tolerated $\beta$-blockers doses, with a left ventricular ejection fraction (LVEF) $\leq 35 \%$, who are in sinus rhythm with a resting heart rate (RHR) of $70 \mathrm{bpm}$ or greater, or have a contraindication to $\beta$-blockers use [7]. Based on two large registries, ivabradine is prescribed in $19.7 \%$ and $21.4 \%$ of HF patients $[\mathbf{8 , 9}$ ].

\subsection{The pharmacological action of ivabradine}

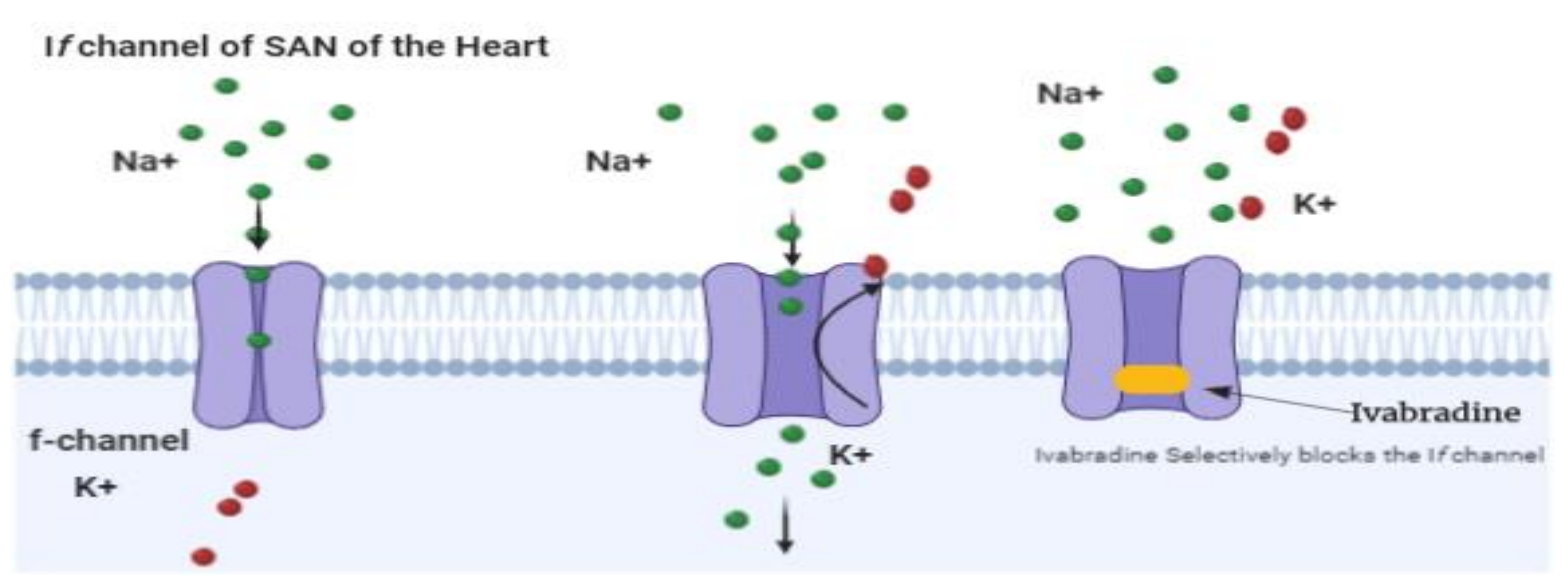

Fig. 1. Mode of action of ivabradine [20]
The sinoatrial node (SAN) is the internal heart pacemaker, which is responsible for cardiac muscle contraction by generating depolarization spontaneously and gradually. Further progression of this depolarization is accelerated by the opening of the Hyperpolarization-activated cyclic nucleotide-gated $(\mathrm{HCN})$ channel in the SAN regulating the current $\left(\mathrm{I}_{f}\right)[\mathbf{1 0}, \mathbf{1 1}]$ resulting in $\mathrm{Na}+$ and $\mathrm{K}+$ influx [12-15].

Ivabradine selectively binds to the inside of the HCN channel, after entering the pacemaker cells and inhibiting their opening and antagonizing their action. Prevention of the inflow of ionic current hinders depolarization and subsequently, reduces heart rate (HR). This blocking effect is proportional to circulating and binding ivabradine through a dose-dependent effect $[15,16]$. Furthermore, the greater HR, the greater the ivabradine induced antagonism, ultimately increasing HR reduction. Selective HR reduction is achieved without impacting cardiac contractility or subsequently modifying blood pressure $[17,18]$ Fig. 1. This reduction in HR has been associated with improved QOL and better prognosis in patients with HF $[4,19]$. The detrimental effects of increased HR in this population is illustrated in Fig. 2. 


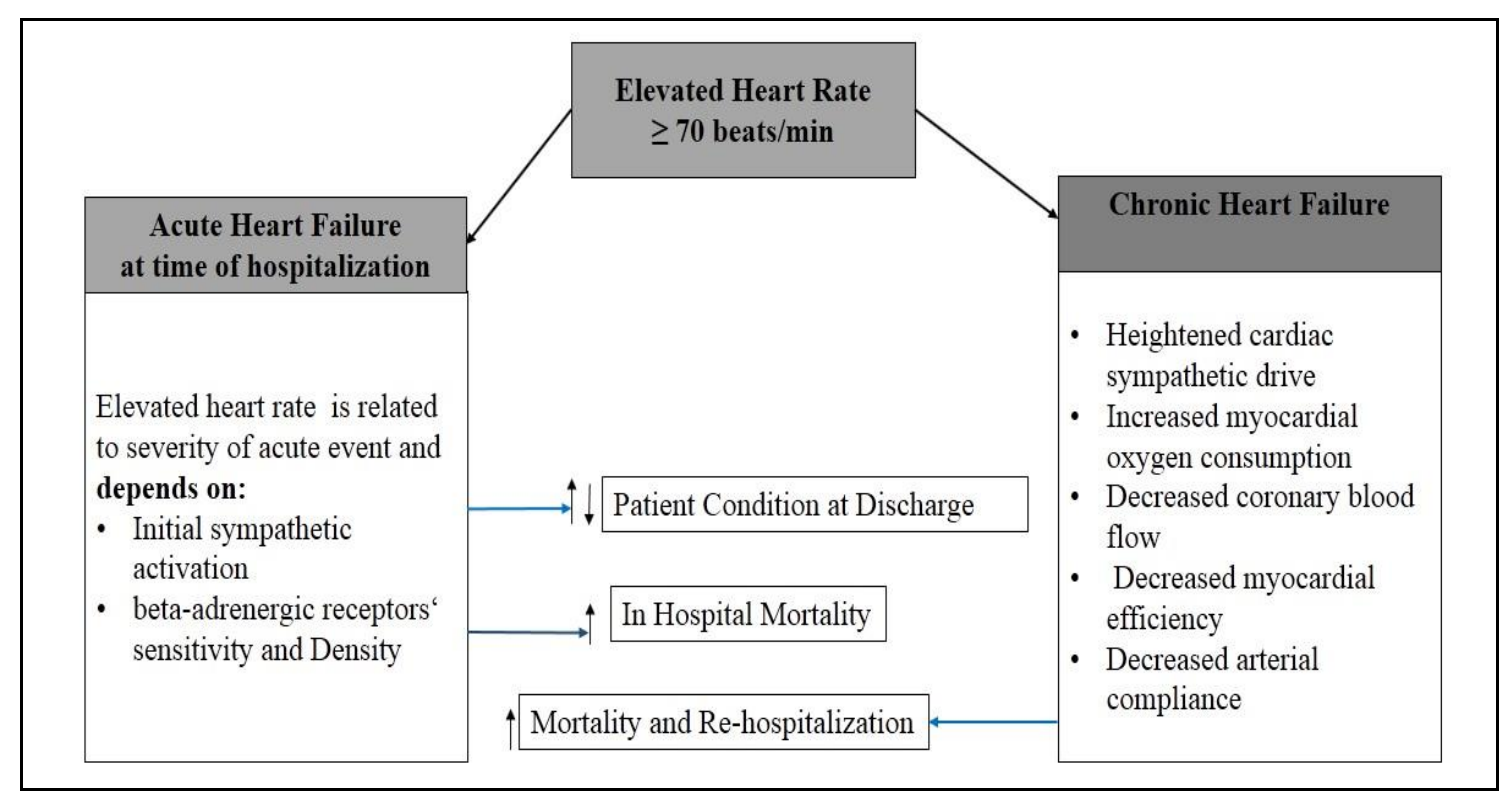

Fig. 2. Impact of increased heart rate in HF [21]

\subsection{Pharmacokinetic Properties of ivabradine}

Ivabradine follows linear pharmacokinetics across its therapeutic range. Following the oral admiration of one dose, rapid absorption is achieved. On an empty stomach, maximum plasma concentration is reached in $60 \mathrm{~min}$. It undergoes $60 \%$ first-pass liver and gastrointestinal breakdown. After meals, the maximum concentration is reached in $2 \mathrm{~h}$ achieving higher plasma concentrations [22]. Ivabradine is highly bound to plasma proteins. The volume of distribution is approximately 100 $\mathrm{L}$ once steady state is reached after multiple-dose administration [23]. Extensive hepatic metabolism by the cytochrome (CYP) system occurs specifically by the enzyme CYP3A4. To avoid drug-drug interactions, concomitant administration of inducers or inhibitors is prohibited [24]. Mild CYP3A4 inhibitors such as metronidazole, omeprazole, and fluoxetine, do not alter ivabradine concentrations [25-27]. Additionally, sildenafil, statins, dihydropyridine calcium- channel blockers, digoxin, and warfarin similarly have insignificant effects. Avoidance of potent inhibitors as azole antifungals, HIV protease inhibitors, and macrolide antibiotics, as well as moderate inhibitors such as diltiazem and verapamil, is mandatory [23]. Phenytoin, carbamazepine, phenobarbital, and rifampin are potent inducers, therefore should be avoided [25, 28, 29]. Dose adjustment is recommended only with moderate but not warranted in mild hepatic impairment, however, ivabradine use is contraindicated in patients with severe hepatic failure [23]. The half-life of ivabradine is $2 \mathrm{~h}$. Metabolism occurs mainly through the liver, with less than $10 \%$ eliminated by the kidney unchanged [30]. The total body clearance of ivabradine is $400 \mathrm{~mL} / \mathrm{min}$. Mild to moderate renal insufficiency has a negligible effect on ivabradine concentrations, therefore, it demands no dose adjustments [31].

\subsection{Ivabradine Recommended Dosage}

There are two dosage strengths $(5 \mathrm{mg}$ and 7.5 $\mathrm{mg}$ ) of ivabradine tablets available in the market for $\mathrm{HF}$ management. A lower dose of $5 \mathrm{mg}$ is initiated 2 times per day, and then the dose is gradually increased up to $7.5 \mathrm{mg}$ twice daily if needed following the failure of reaching target 
HR within two weeks of treatment. A further reduction to $2.5 \mathrm{mg}$ twice daily can be made if adverse effects such as bradycardia or dizziness are experienced. For patients older than $75 \mathrm{mg}$ an initial dose (2.5 mg twice daily) is sufficient [11, 23].

\subsection{Safety and Toxicity}

Ivabradine is safe and well-tolerated alone or in combination with $\beta$-blockers or cardiovascular medication and patients with cardiovascular diseases [32-34]. It is not contraindicated in patients with other chronic respiratory and endocrinal diseases $[35,36]$. It may be used safely with mild hypotensive patients due to the absence of blood pressure reduction. Its common side effects are dizziness, fatigue, atrial fibrillation, bradycardia and visual symptoms [37]. Less than $4 \%$ of patients on ivabradine experience bradycardia, although this usually doesn't require discontinuation of the drug [33, 37, 38]. A sub-study of the BEAUTIFUL trial confirmed the safety of co-administration of ivabradine with $\beta$-blockers [39].

There was no evidence in an increase in the risk of arrhythmia development with ivabradine usage, despite efficacy in successfully reducing HR [39]. Transient vision disturbance related to ivabradine is caused by the effect of ivabradine on ion channels in the retina $\left(\mathrm{I}_{h}\right)$ current, identical to the target SAN $\left(\mathrm{I}_{f}\right)$ channel. These reported symptoms were nonfrequent and were considered mild and reversible with time not requiring treatment withdrawal $[37,40,41]$. Ivabradine administration should be avoided in patients with decompensated HF, severe hypotension, patients with SA, and 3rd-degree AV block [42].

\subsection{Clinical trials of ivabradine in HFrEF}

\subsubsection{The BEAUTIFUL investigator's study}

The first study investigating the impact of ivabradine treatment on morbidity, mortality and reducing RHR in HF and coronary artery disease (CAD) was conducted by the BEAUTIFUL (morbidity-mortality evaluation of ivabradine in patients with CAD and LV dysfunction) [38] This multiple center trial was a randomized, placebo-controlled study with 10918 patients with ischemic cardiovascular disease and reduced EF $(<40 \%)$. The primary outcome was a composite of cardiovascular death, hospitalization and major adverse cardiac events. The patients continued therapy with ACEIs/(ARBs) agents as well as $\beta$-blockers. Despite that ivabradine was ineffective in reducing the primary composite endpoint compared to placebo, subgroup analysis of patients with HR greater than $70 \mathrm{bpm}$, revealed that the risk for acute MI and coronary revascularization was reduced by $36 \%$ and by $30 \%$, respectively.

\subsubsection{CARVIVA-HF}

In the CARVIVA HF trial, the impact of carvedilol, ivabradine, and their combined effect on exercise capacity was investigated in patients with $\mathrm{HF}$ receiving maximal evidence-based doses of ACEIs [43]. All $\beta$-blockers were discontinued before randomization. Patients were divided into 3 groups: ivabradine (maximum $7.5 \mathrm{mg}$ twice daily), carvedilol (maximum $25 \mathrm{mg}$ twice a day), or ivabradine (maximum $5 \mathrm{mg}$ ) and carvedilol (maximum $12.5 \mathrm{mg}$ ), twice daily. The treatment duration was 12 weeks. Evidence from this trial suggested that both treatments with ivabradine as a single agent or ivabradine plus carvedilol improved the exercise capacity and quality of life in HF patients with guideline maximum tolerated doses of ACEIs.

\subsubsection{SHIFT}

Systolic HF treatment with the $\left(\mathrm{I}_{f}\right)$ inhibitor ivabradine trial is one of the large trials studying ivabradine administration in the long-term. This 
study assessed the add on the impact of ivabradine to tolerated guideline therapy on the clinical outcomes of HF patients with sinus rhythm and reduced EF $<35 \%$. The twice-daily dosing of ivabradine was compared to placebo treatment, starting with a minimal dose of $5 \mathrm{mg}$, followed by a gradual dose increase. Results showed improvement in the primary outcomes which were hospitalization, mortality, and morbidity. A reduction in HR was reported in the Ivabradine versus placebo arm. Most patients were on $\beta$-blockers but not the maximal dose. A follow up period of almost 2 years was reached and the positive outcomes were more pronounced in patients with $\mathrm{RHR} \geq 77 \mathrm{bpm}$ and less noticeable in those receiving less than half the target dose of $\beta$-blockers [37]. Overall, the evidence from these findings validates ivabradine use in HF patients with systolic dysfunction, along with $\beta$-blockers administration. Additionally, safety was evaluated and proved.

To sum up, the two-main long-term studies BEAUTIFUL and SHIFT justified the use of ivabradine in patients with systolic dysfunction. The BEAUTIFUL study evaluated ivabradine effect on morbidity and mortality in Coronary Heart Disease (CHD) patients with associated LV dysfunction, while the SHIFT study assessed its efficacy in the reduction of cardiovascular mortality and hospitalization for worsening HF in patients with chronic HF and LV systolic dysfunction, who are already optimized on guideline-directed medical therapy.

Based on this evidence, ESC guideline recommended the use of ivabradine in persistently symptomatic patients with LVEF $\leq 35 \%$, and sinus rhythm (HR $\geq 70 \mathrm{bpm}$ ) even whilst receiving maximum tolerated dose of $\beta$ blockers or in the presence of contra-indications to $\beta$-blockers usage $[\mathbf{1}, \mathbf{1 9}]$.

\subsubsection{LIVE (LIFE)}

Elderly patients are known to have multiple comorbidities combined with polypharmacy. Therefore, a multicenter study conducted in the United Kingdom (UK) evaluated elderly HF patients with age $\geq 70$ years of initiating ivabradine. The results showed that after 6 months of treatment, patients' Health-Related Quality of Life (HRQoL) and functional status were improved. The data of the latter study was presented after an average of 15 months $[\mathbf{4 4 , 4 5 ]}$. The result of using ivabradine in the long-term showed that it was well tolerated in this population. The findings of this study support the data published in the SHIFT study. However, this study has limitations as it was an open-label, prospective, observational study. Accordingly, as ivabradine was already included in the international guidelines at the time the study started, it is considered unethical to conduct a placebo-controlled trial. Moreover, adherence to ivabradine cannot be excluded [1].

\subsection{Clinical trials of ivabradine in $\mathrm{HFpEF}$}

A study published in 2017 enrolled patients with $\mathrm{HFpEF}$ and found a significant difference in HR reduction in ivabradine arm versus placebo arm from the baseline after 8 months follow up. Furthermore, there was a significant improvement in total mitral flow duration and left atrial volume index (LAVI) in the ivabradine group compared to the placebo group. However, those improvements in echocardiography were not reflected in other outcomes including the functional capacity and NT-proBNP levels. Therefore, the benefits of ivabradine in diastolic $\mathrm{HF}$ are lacking. More clinical trials on HFpEF cohorts are required to sufficiently assess whether HR reduction may benefit these groups of patients [46].

In contrast, another study conducted on patients with HFpEF reported that the patients 
treated with ivabradine showed a significant reduction in RHR at follow up, however, no significant change was observed in blood pressure. Besides, while LV diastolic volume slightly increased, LV systolic volume was not significantly reduced. Ivabradine administration resulted in improvement in both the stroke volume and EF\%. Finally, this trial concluded that ivabradine use as an add-on to guidelinedirected medical therapy for 3 months in patients with HFpEF can reduce LV diastolic dysfunction, these positive findings correlate with the clinical improvement of these patients [47].

\subsection{Novel perceptions of ivabradine in heart failure}

Quality of life, global assessment and symptoms are the most common patient-reported outcomes (PRO) in patients with HF. However, their influence on guideline-directed medical therapy (GDMT) in HF patients on ivabradine is under-investigated in clinical trials. Recent research studied the impact of ivabradine on PRO in LVEF- HF patients with a baseline HR more than $77 \mathrm{bpm}$. This trial revealed that the addition of ivabradine to standard HF therapy significantly improved QOL decreased cardiovascular mortality and hospital admission for decompensated $\mathrm{HF}$ and affected $\mathrm{LV}$ dimensions positively on long-term treatment. These findings confirm that the addition of ivabradine to recommended standard therapy in patients with baseline HR more than $77 \mathrm{bpm}$ has a great impact on PRO [48].

Also, due to ivabradine's mechanism of action as a negative chronotropic drug, the possibility of its suitability for use in HF patients with permanent $\mathrm{AF}$ has been considered. Although this is not yet proven in clinical practice, currently there is an ongoing project entitled BRAKE-AF project. The objective of the project is to assess the possible role of ivabradine together with other therapeutic options used to manage the function of the heart in AF [49].

Additionally, there are ongoing studies to emphasize that ivabradine has a positive inotropic effect, one of these studies were done on isolated rat's heart. Ivabradine increased the $\mathrm{Ca}^{2+}$ reuptake rates of sarcoplasmic/endoplasmic reticulum calcium ATPase 2a (SERCA2a), lowered the diastolic $\mathrm{Ca}^{2+}$ level and inhibited $\mathrm{Na}^{+} / \mathrm{Ca}^{2+}$ exchange. Ivabradine contributed to increasing the action potential duration and sarcoplasmic reticulum $\mathrm{Ca}^{2+}[\mathbf{5 0}]$.

Also, a recent study found the role of ivabradine in muscular diseases. The study was conducted on a group of patients with muscular diseases including heart and skeletal muscle dystrophy using ivabradine. Their findings proved that ivabradine was tolerated and may reduce symptoms, morbidity, and mortality in this population [51].

Finally, concerning the cost-effectiveness of ivabradine in HFrEF patients, there is a published study conducted on Thailand population. This study suggested that the add-on of ivabradine to guideline-directed medical therapy was a costeffective treatment plan in Thailand HFrEF patients with a baseline RHR $\geq 77$ bpm [52].

\section{Conclusion}

Ivabradine an inhibitor of the cardiac pacemaker $\left(\mathrm{I}_{f}\right)$ current channel, in the Sino-atrial node, is the only approved medication reducing HR without modifying blood pressure. It is considered safe and tolerable for chronic HFrEF. Concerning patients with $\mathrm{HFpEF}$, conflicting results from limited trials using ivabradine are insufficient to confirm its benefit in this group of patients. Long term studies are required in the future to verify outcomes from previous studies. Moreover, the role of ivabradine in HF patients with AF is currently under investigation. 


\section{Declarations}

All authors declared that no relevant affiliations or financial association with any corporation or individual with a commercial interest in or financial conflict with the subject matter or resources reviewed in the manuscript.

Ethics approval and consent to participate: Not applicable

\section{Consent to publish}

The authors have all approved the final manuscript and decided on the publishing of the submitted work in the APS journal.

\section{Availability of data and materials}

All data generated or analyzed during this study are included in this published article in the main manuscript.

\section{Competing interests}

The authors have all declared that no competing interests exist

\section{Funding Statement}

No funding source was accepted.

\section{List of abbreviations}

HF, Heart Failure; ESC, European Society of Cardiology; HFrEF, Heart Failure with Reduced Ejection Fraction; HFpEF, Heart Failure with Preserved Ejection Fraction; ACEi, AngiotensinConverting Enzyme Inhibitors; ARBs, Angiotensin Receptor Blockers; MRAs, Mineralocorticoid Antagonists; AHF, Acute Heart Failure; CHF, Chronic Heart Failure; LVEF, Left Ventricular Ejection Fraction; RHR, Resting Heart Rate; SAN, Sinoatrial Node; HCN, Hyperpolarization-activated cyclic nucleotidegated; CYP, cytochrome; HIV, Human immunodeficiency Virus; CAD, Coronary Artery Disease; BEAUTIFUL, Morbidity-mortality evaluation of the $\left(\mathrm{I}_{f}\right)$-inhibitors ivabradine in patients with $\mathrm{CAD}$ and left ventricular dysfunction; MI, Myocardial Infarction; CARVIVA-HF, Carvedilol, ivabradine or their combination on exercise capacity in patients with HF; SHIFT, The Systolic Heart failure treatment with the $\left(\mathrm{I}_{f}\right)$ inhibitor ivabradine Trial; CHD, Coronary Heart Disease; HRQoL, Health-Related Quality of Life; LAVI, left Atrial Volume Index; NT-proBNP, The N-terminal prohormone of brain natriuretic peptide; IVA, Ivabradine; PRO, Patient-reported outcomes; GDMT, Guideline Directed Medical Therapy; Bpm, Beat per Minute; QOL, Quality of Life; AF, Atrial Fibrillation; BRAKE-AF, Ivabradine block of Funny Current for Heart Rate Control in Permanent Atrial Fibrillation.

\section{REFERENCES}

1. Ponikowski P, Voors AA, Anker SD, et al. 2016 ESC Guidelines for the diagnosis and treatment of acute and chronic heart failure: The Task Force for the diagnosis and treatment of acute and chronic heart failure of the European Society of Cardiology (ESC). Developed with the special contribution of the Heart Failure Association (HFA) of the ESC. Eur J Heart Fail. 2016; 18:891975.https://doi.org/10.1002/ejhf.592

2. Rosamond WD, Johnson A. Trends in Heart Failure Incidence in the Community: A Gathering Storm. Circulation. 2017; 135:1224-

1226.https://doi.org/10.1161/CIRCULATION AHA.117.027472

3. Savarese G, Lund LH. Global Public Health Burden of Heart Failure. Card Fail Rev. 2017; 3:7-11.https://doi.org/10.15420/cfr.2016:25:2

4. Bocchi EA, Salemi VMC. Ivabradine for treatment of heart failure. Expert Opinion on Drug Safety. 2019; 18:393402.10.1080/14740338.2019.1612873

5. Dharmarajan K, Rich MW. Epidemiology, Pathophysiology, and Prognosis of Heart 
Failure in Older Adults. Heart Fail Clin. 2017; 13:417426.https://doi.org/10.1016/j.hfc.2017.02.001

6. Owan TE, Redfield MM. Epidemiology of diastolic heart failure. Prog Cardiovasc Dis. 2005; 47:320332.https://doi.org/10.1016/j.pcad.2005.02.01 0

7. Hassanein M, Abdelhamid M, Ibrahim B, et al. Clinical characteristics and management of hospitalized and ambulatory patients with heart failure-results from ESC heart failure long-term registry-Egyptian cohort. ESC heart failure. 2015; 2:159167.https://doi.org/10.1002/ehf2.12046

8. de Frutos F, Mirabet S, Ortega-Paz L, et al. Management of Heart Failure with Reduced Ejection Fraction after ESC 2016 Heart Failure Guidelines: The Linx Registry. ESC Heart Failure. 2020.https://doi.org/10.1002/ehf2.12567

9. Crespo-Leiro MG, Segovia-Cubero J, González-Costello J, et al. Adherence to the ESC heart failure treatment guidelines in Spain: ESC heart failure long-term registry. Rev Esp Cardiol 2015; 68:785793.https://doi.org/10.1016/j.rec.2015.03.008

10. Iwai S, Markowitz S, Lerman B. Electrophysiology of cardiac arrhythmias. In: Rosendorff C, editor. Essential cardiology principles and practice. Third ed New York: Springer; 2013:

11. Mueller-Werdan U, Stoeckl G, Werdan K. Advances in the management of heart failure: the role of ivabradine. Vasc Health Risk Manag 2016; 12:453.https://doi.org/doi:10.2147/VHRM.S9 0383

12. DiFrancesco D. Cardiac pacemaker I(f) current and its inhibition by heart rate- reducing agents. Curr Med Res Opin. 2005; 21:1115-

1122.https://doi.org/10.1185/030079905x505 43

13. Postea O, Biel M. Exploring HCN channels as novel drug targets. Nat Rev Drug Discov. 2011; 10:903.https://doi.org/10.1038/nrd3576

14. Wahl-Schott C, Fenske S, Biel M. HCN channels: new roles in sinoatrial node function. Curr Opin Pharmacol. 2014; 15:8390.https://doi.org/10.1016/j.coph.2013.12.005

15. Satriani L, Mannaioni G, Masi A, Romanelli MN, Cerbai E. The HyperpolarizationActivated Cyclic Nucleotide-Gated Channels: from Biophysics to Pharmacology of a Unique Family of Ion Channels. Pharmacological reviews. 2017; 69:354395.https://doi.org/10.1124/pr.117.014035

16. Bucchi A, Baruscotti M, Nardini M, et al. Identification of the molecular site of ivabradine binding to HCN4 channels. PLoS One. 2013; 8:e53132.https://doi.org/10.1371/journal.pone .0053132

17. Colin $\mathrm{P}$, Ghaleh $\mathrm{B}$, Hittinger $\mathrm{L}$, et al. Differential effects of heart rate reduction and $\beta$-blockade on left ventricular relaxation during exercise. Am J Physiol Heart Circ Physiol. 2002; 282:H672H679.https://doi.org/10.1152/ajpheart.00547.2 001

18. Manz M, Reuter M, Lauck G, Omran H, Jung W. A single intravenous dose of ivabradine, a novel If inhibitor, lowers heart rate but does not depress left ventricular function in patients with left ventricular dysfunction. Cardiol. 2003 ;

100:149-

155.https://doi.org/10.1159/000073933

19. Haboub M, Arous S, Benouna E, Drighil A, Azzouzi L, Habbal R. Symptoms and quality 
of life improvement in heart failure patients with reduced LVEF taking ivabradine. Arch Cardiovasc Dis Suppl. 2020; 12:51.https://doi.org/10.1016/j.acvdsp.2019.0 9.110

20. Canet E, Lerebours G, Vilaine JP. Innovation in coronary artery disease and heart failure: clinical benefits of pure heart rate reduction with ivabradine. Ann N Y Acad Sci. 2011; 1222:90-99.https://doi.org/10.1111/j.17496632.2011.05960.x

21. Metra M. Tachycardia after a heart failure hospitalization: another piece of the puzzle? JACC Heart Failure. 2013; 1:497499.https://doi.org/10.1016/j.jchf.2013.10.003

22. Servier. Procoralan Summary of Product Characteristics [online]Available from URL: http://www.medicines.org.uk/emc/medicine/1 7188/SPC/.Accessed 26 Aug 2018.:

23. Thousand Oaks, CA; Amgen I. CORLANOR (ivabradine) [package insert]. 2017:

24. Chow SL, Page RL, 2nd, Depre C. Role of ivabradine and heart rate lowering in chronic heart failure: guideline update. Expert Rev Cardiovasc Ther. 2018; 16:515526.https://doi.org/10.1080/14779072.2018.1 489235

25. Portoles A, Calvo A, Terceira A, et al. Lack of Pharmacokinetic Interaction Between Omeprazole or Lansoprazole and Ivabradine in Healthy Volunteers: An Open-Label, Randomized, Crossover, Pharmacokinetic Interaction Clinical Trial. J Clin Pharmacol. 2006; 46:11951203.https://doi.org/10.1177/0091270006291 624

26. Vase L, Muntean D, Popa A, et al. Pharmacokinetic interaction between ivabradine and ciprofloxacin in healthy volunteers. Stud U Babes-Bol Che. 2009;
$54: 265-271$

27. Vlase L, Popa A, Neag M, Muntean D, Leucuta SE. Pharmacokinetic interaction study between ivabradine with fluoxetine or metronidazole in healthy volunteers. Farmacia. 2010; 58:471-477

28. Vlase L, Neag M, Popa A, Muntean D, Bâldea I, Leucuta S. Pharmacokinetic interaction between ivabradine and carbamazepine in healthy volunteers. J Clin Pharm Ther. 2011; 36:225-229. https://doi.org/10.1111/j.1365-

2710.2010.01170.x

29. Vlase L, Popa A, Neag M, Muntean D, Leucuta SE. Pharmacokinetic interaction between ivabradine and phenytoin in healthy subjects. Clin Drug Invest. 2012; 32:533538.https://doi.org/10.1007/BF03261904

30. Choi HY, Noh Y-H, Cho S-H, et al. Evaluation of pharmacokinetic and pharmacodynamic profiles and tolerability after single $(2.5,5$, or $10 \mathrm{mg})$ and repeated (2.5, 5, or $10 \mathrm{mg}$ bid for 4.5 days) oral administration of ivabradine in healthy male Korean volunteers. Clin Ther. 2013; 35:819835.https://doi.org/10.1016/j.clinthera.2013.0 4.012

31. Deedwania P. Selective and specific inhibition of If with ivabradine for the treatment of coronary artery disease or heart failure. Drugs. 2013; 73:15691586.https://doi.org/10.1007/s40265-0130117-0

32. Borer JS, Fox K, Jaillon P, Lerebours G, Ivabradine Investigators $G$. Antianginal and antiischemic effects of ivabradine, an I(f) inhibitor, instable angina: a randomized, double-blind, multicentered, placebocontrolled trial. Circulation. 2003; 107:817823.https://doi.org/10.1161/01.cir.000004814 3.25023 .87 
33. Tardif JC, Ford I, Tendera M, Bourassa MG, Fox K, Investigators I. Efficacy of ivabradine, a new selective I(f) inhibitor, compared with atenolol in patients with chronic stable angina. Eur Heart J. 2005; 26:25292536.https://doi.org/10.1093/eurheartj/ehi586

34. Ruzyllo W, Tendera M, Ford I, Fox KM. Antianginal efficacy and safety of ivabradine compared with amlodipine in patients with stable effort angina pectoris: a 3-month randomized, double-blind, multicentre, noninferiority trial. Drugs. 2007; 67:393405.https://doi.org/10.2165/00003495200767030-00005

35. Borer JS, Tardif J-C. Efficacy of ivabradine, a selective If inhibitor, in patients with chronic stable angina pectoris and diabetes mellitus. Am J Cardiol. 2010; 105:2935.https://doi.org/10.1016/j.amjcard.2009.08. 642

36. Tendera M, Borer JS, Tardif J-C. Efficacy of If inhibition with ivabradine in different subpopulations with stable angina pectoris. Cardiol. 2009; 114:116125.https://doi.org/10.1159/000219938

37. Swedberg K, Komajda M, Bohm M, et al. Ivabradine and outcomes in chronic heart failure (SHIFT): a randomized placebocontrolled study. Lancet. 2010; 376:875885.https://doi.org/10.1016/S01406736(10)61198-1

38. Fox K, Ford I, Steg PG, Tendera M, Ferrari $\mathrm{R}$, Investigators $\mathrm{B}$. Ivabradine for patients with stable coronary artery disease and leftventricular systolic dysfunction (BEAUTIFUL): a randomized, double-blind, placebo-controlled trial. Lancet. 2008; 372:807-816.https://doi.org/10.1016/S01406736(08)61170-8

39. Tendera M, Talajic M, Robertson M, et al.
Safety of ivabradine in patients with coronary artery disease and left ventricular systolic dysfunction (from the BEAUTIFUL Holter Substudy). Am J Cardiol. 2011; 107:805811.https://doi.org/10.1016/j.amjcard.2010.10 .065

40. Amosova E, Andrejev E, Zaderey I, Rudenko U, Ceconi C, Ferrari R. Efficacy of ivabradine in combination with Beta-blocker versus uptitration of Beta-blocker in patients with stable angina. Cardiovasc Drugs Ther. 2011; 25:531-537.https://doi.org/10.1007/s10557011-6327-3

41. Werdan K, Ebelt H, Nuding S, Hopfner F, Hack G, Muller-Werdan U. Ivabradine in combination with beta-blocker improves symptoms and quality of life in patients with stable angina pectoris: results from the ADDITIONS study. Clin Res Cardiol. 2012; 101:365-373.https://doi.org/10.1007/s00392011-0402-4

42. FDA. US Food and Drug Administration Ivabradine Drug Label. 2015:

43. Volterrani M, Cice G, Caminiti G, et al. Effect of Carvedilol, Ivabradine or their combination on exercise capacity in patients with Heart Failure (the CARVIVA HF trial). Int J Cardiol. 2011; 151:218224.https://doi.org/10.1016/j.ijcard.2011.06.0 98

44. Zachariah D, Stevens D, Sidorowicz G, et al. Quality of life improvement in older patients with heart failure initiated on ivabradine: Results from the UK multi-centre LIVE: LIFE prospective cohort study. Int J Cardiol. 2017; 249:313318.https://doi.org/10.1016/j.ijcard.2017.08.0 01

45. Birkhoelzer S, Stevens D, Zachariah D, Taylor J, Rowell N, Kalra PR. Ivabradine 
tolerability in heart failure. J Geriatr Cardiol. 2018; 15:708-709. https://doi.org/10.11909/j.issn.1671-

5411.2018.11.007

46. Komajda M, Isnard R, Cohen-Solal A, et al. Effect of ivabradine in patients with heart failure with preserved ejection fraction: the EDIFY randomized placebo-controlled trial. Eur J Heart Fail. 2017; 19:1495-1503. https://doi.org/10.1002/ejhf.876

47. Cacciapuoti F, Magro VM, Caturano M, Lama D, Cacciapuoti F. The role of Ivabradine in Diastolic Heart Failure with preserved Ejection Fraction. A DopplerEchocardiographic study. J Cardiovasc Echogr. 2017; 27:126131.https://doi.org/10.4103/jcecho.jcecho_6_1 7

48. Bouabdallaoui N, O'Meara E, Bernier V, et al. Beneficial effects of ivabradine in patients with heart failure, low ejection fraction, and heart rate above $77 \mathrm{bpm}$. ESC heart failure. 2019.https://doi.org/10.1002/ehf2.12513

49. Fontenla A, López-Gil M, TamargoMenéndez $\mathrm{J}$, et al. Ivabradine for chronic heart rate control in persistent atrial fibrillation. Design of the BRAKE-AF project. Revista Española de Cardiología (English Edition). 2019.https://doi.org/10.1016/j.rec.2019.09.00

4

50. Xie M, Huang H-L, Zhang W-H, et al. Increased sarcoplasmic/endoplasmic reticulum calcium ATPase 2a activity underlies the mechanism of the positive inotropic effect of ivabradine. Exp Physiol n/a. https://doi.org/10.1113/ep087964

51. Rajendram R, AlDhahri F, Mahmood N, Kharal M. The use of ivabradine in a patient with inappropriate sinus tachycardia and cardiomyopathy due to limb-girdle muscular dystrophy type 2I. BMJ Case Reports CP. 2020; 13.http://dx.doi.org/10.1136/bcr-2019230647

52. Krittayaphong R, Yadee J, Permsuwan U. Cost-Effectiveness Analysis of the Adjunctive Therapy of Ivabradine for the Treatment of Heart Failure with Reduced Ejection Fraction. Clinicoecon Outcomes Res. 2019; 11:767777.https://doi.org/10.2147/CEOR.S226568 